\title{
DUV Interferometry for Micro and Nanopatterned Surfaces
}

\author{
Olivier Soppera et al. ${ }^{*}$ \\ Institut de Sciences des Matériaux de Mulhouse, CNRS LRC 7228, Mulhouse,
}

France

\section{Introduction}

Recent developments in nanoscience and nanotechnology were strongly supported by advances in nanofabrication. Controlled patterning of nanostructured materials has become increasingly important because of the ever-decreasing dimensions of various devices, including those used in electronics, optics, photonics, biology, electrochemistry, and electromechanics (Henzie et al., 2004; Fan et al., 2006). Today, the production of structures with typical dimension in the 1 to $100 \mathrm{~nm}$ range with engineered physical and chemical properties is challenging.

Different nano-fabrication techniques have been reported in the literature (Nie \& Kumacheva, 2008). Recent examples include optical lithography (Cotton et al., 2009), electron beam lithography (Gonsalves et al. 2009), X-ray lithography (Im et al., 2009), laser writing (Soppera et al., 2008), scanning probe techniques (including optical near-field lithography (El Ahrach et al., 2007), pen nanolithography (Cai \& Ocko, 2005), dip-pen lithography (Christman et al., 2009), nanoshaving (Seo \& Borguet, 2006) and thermal scribing (Lee et al., 2008)), microcontact printing (Huh et al., 2009), micro-phase separation of block copolymers (Greater et al., 2007), dewetting (Yoon et al., 2008), nanoimprint lithography (He et al., 2009) or electrochemical nanopatterning (Jegadesan et al., 2006). The major remark is that the size of the achievable patterns is strongly dependent of the technique used and can vary between the micrometer to the sub-10 nanometre length scale. This point is a serious limitation when different length scales are needed. Furthermore, in most cases these techniques suffer from different material requirements and limited dimensions of the patterned surface.

In this context, interferometric lithography appears of high interest when periodical patterns are needed. Indeed, interferometric techniques can be considered as massively parallel nanofabrication techniques since patterns can be obtained over large area within a single exposure. Moreover, the recourse to wavelength in the Deep-UV range (DUV corresponds

\footnotetext{
*Ali Dirani1,2, Fabrice Stehlin'1, Hassan Ridaoui1,3, Arnaud Spangenberg1, Fernand Wieder ${ }^{1}$ and Vincent Roucoules ${ }^{1}$ ${ }^{1}$ Institut de Sciences des Matériaux de Mulhouse, CNRS LRC 7228, Mulhouse, France ${ }^{2}$ Université Catholique de Louvain, Division of Bio- and Soft Matter, Belgique

${ }^{3}$ CEA, Laboratoire d'Innovation pour les Technologies des Energies Nouvelles et les nanomatériaux / DEHT/ LPCE, Grenoble, France
} 
to $\lambda<300 \mathrm{~nm}$ ) allows producing periodic nanostructures with typical dimension down to several tens of nm.

The aim of this chapter is to review some recent works about DUV interferometric lithography nanofabrication. In the first part, a brief introduction to interferometric lithography will allow illustrating its interest and main applications. The second part will be dedicated to applications with organic materials (polymers) that have been widely used for micro and nanopatterning with such a technique. However, organic materials present some inherent limitations that have justified many efforts during the last years to developed inorganic materials prepared by sol-gel technique. This will be the topic of the third part of this chapter.

\section{DUV interferometry}

\subsection{Introduction}

The needs for simple, fast and versatile techniques for micro- and nanomachining have accounted for many works during the last years. The most active sector in this field has been the microelectronics industry. Researches in this area were essentially motivated by finding new solutions to follow the trend towards a constant decrease of the size of the transistors as stated in the "Moore's law" (Moore, 1965). To reach these objectives, the recourse to deeper wavelengths has been proposed. Today, the most used wavelength for chips manufacturing is $193 \mathrm{~nm}$ provided by ArF excimer lasers. In this case, the use of short wavelength allows decreasing the limitations linked to diffraction. Patterns with dimensions as small as $22 \mathrm{~nm}$ can be produced by industrial machines (steppers) on $300 \mathrm{~mm}$ diameter Silicon wafers. However, these high performance lithographic tools are restricted to production use and complex patterns due to their very high cost.

For these reasons, there is a parallel need of less sophisticated setups but able to produce sub-100 nm structures on relatively wide surfaces. For some applications, the structures do not need to be complex and can be limited to a regular replication of simple shapes like dots or lines. For the fabrication of such periodical nanostructures, interferometric techniques fulfil most of the needed requirements.

Interferometry consists in combining two or more monochromatic, coherent and polarized beams to produce an interference pattern. This technique is sometimes also called holography. The spatially controlled irradiation is used to induce a local modification of the material that can be either a photocrosslinking or an ablation due to different molecular mechanisms.

The period $\mathrm{p}$ is given by the following relation:

$$
p=\frac{\lambda}{2 \cdot n \cdot \sin \theta}
$$

Where $\lambda$ is the wavelength, and $n$ is the refractive index of the medium in which the two beams are recombined and $\theta$ is the half-angle between the two beams.

The recourse to short wavelengths $(248 \mathrm{~nm}, 193 \mathrm{~nm})$ allows producing periods as low as 100 $\mathrm{nm}$ in air (Charley et al., 2006), meaning that this route is competitive in terms of resolution with most advanced photolithography industrial tools. In comparison, the alternative to mask projection imaging is limited to gratings with periods $>1 \mu \mathrm{m}$ (Mihailov \& Gower, 1994). Interferometric techniques are much more adapted for sub-micron structuring. 
Interferometry in the DUV range has been enabled by the development of excimer lasers that have two main advantages: first, the use of short wavelengths is an effective way to provide the requested resolution since the period is directly proportional to the wavelength. Secondly, DUV wavelength permits direct writing via photoinduced processes provoked by high-energy photons. Examples of suitable materials for such wavelengths will be given in the following sections.

On the experimental point of view, one of the difficulties for interferometry in the DUV range is due to the low coherence of available DUV lasers. As an example, typical coherence of ArF lasers is limited to a few hundreds of microns, which justifies efforts to develop specific experimental setup for short wavelengths (Figure 1):

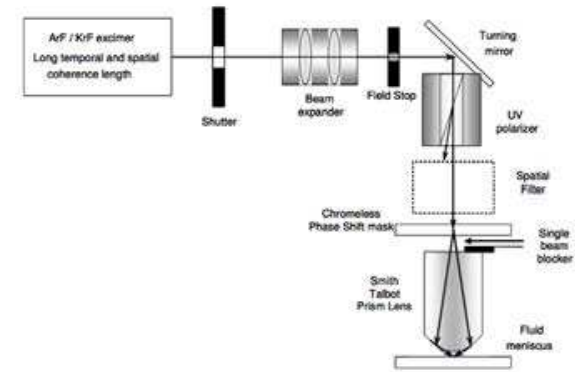

a)

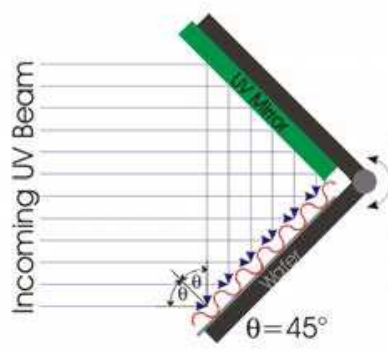

b)

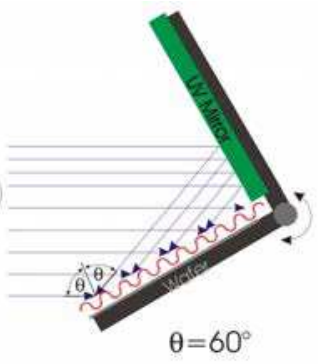

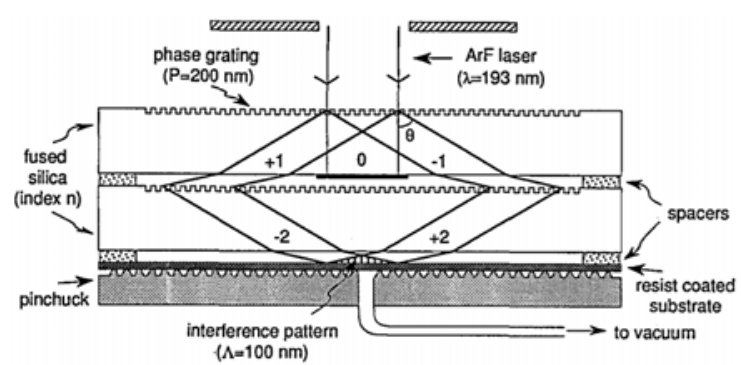

c)

Fig. 1. Example of interferometric lithography configuration: a) Talbot prism (Bourov et al., 2004), b) Lloyd setup (Raub \& Brueck, 2003) and c) achromatic holographic configuration (Yen et al., 1992)

- Holographic grating formation has been proposed (Askins et al., 1992; Archambault et al., 1993). However, in all cases, it has been necessary to increase the spatial coherence and decrease the spectral emission band width of excimer lasers, which considerably increase the laser system complexity and demonstrations have been mostly done with $248 \mathrm{~nm}$ lasers.

- Several systems based on Compact size Talbot prism have been developed to fit with the different excimer wavelengths $(193 \mathrm{~nm}, 248 \mathrm{~nm})$, with periods down to $90 \mathrm{~nm}$ (Bourov et al., 2004). The reduced dimensions of the system are compatible with coherence requirements linked to excimer lasers and such configuration is compatible with immersion. 


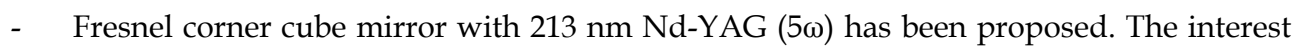
of this configuration is to be compatible with immersion. However, it is limited in laser sources since it requires spatial coherence higher than what is available with excimer lasers (Raub \&Brueck, 2003).

- A fourth approach relies on the use of diffraction element designed to generate two coherent beams. This was the most widely used method since it is relatively simple and compatible with the low coherence of the excimer gratings (spectral line widths of $1 \mathrm{~nm}$ and spatial coherence size $<300 \mu \mathrm{m}$ ). This last route has been studied from theoretical and practical point of view. Among other interesting works, specific studies have investigated the effect of the 0th order (non-diffracted beam in the direction of the incident beam) on the spatial light distribution (Xiong et al., 1999; Dyer et al., 1995). It is shown that even small contributions from orders other than the \pm 1 can produce significant deviations from the distribution expected for the ideal two-beam cases and it is thus to be considered with particular care.

One very elegant way to cope with this problem has been proposed by Yen et al (Yen et al., 1992). It consists in using an achromatic configuration. In this case, two matched fused silica phase gratings were employed and, the demonstration of $100 \mathrm{~nm}$ period grating was achieved using an ArF excimer laser. High contrast fringes were obtained with a depth-offocus compatible with practical applications. Here, the 0th order can be physically blocked providing a perfect sinusoidal light pattern on the photosensitive resin. The advantages of the achromatic configuration are obvious for laser sources with limited coherence. Since then, this technique has been used by several research teams. Recently, Bourgin et al. (Bourgin et al., 2009) have proposed an integrated solution providing the 2 gratings on the same substrate, which simplifies the alignments.

Significant progresses in resolution have also been achieved using immersion technique. Using an immersion fluid between the phase mask and the sample, it is possible to increase the numerical aperture and thus decrease the period (see Eq. 1). The most widely used fluid for immersion is water since water is transparent at $193 \mathrm{~nm}$. High refractive index fluids have demonstrated their interest to reach resolutions as low as $32 \mathrm{~nm} \mathrm{HP}$ corresponding to the $65 \mathrm{~nm}$ node in microelectronics (Santillan et al., 2006).

\subsection{Applications of periodical structures}

Most of the applications of periodical micro- or nanostructures are in the field of optics and photonics. Indeed, such structures with periods in the range, or under, the wavelength of light exhibit strong interaction with light with specific effects.

It is not possible to mention here all the applications of gratings that could be provided by means of DUV laser interferometry. The most important ones are probably linked to spectroscopy, especially for high resolution spectrometers for astronomy (Heilmann et al., 2004), low-loss polarisers, grating for laser pulses shortening, motion sensors, displays (Braun, 2002), microlasers (Wegmann, 1998; Schon, 2000), white light processing like antireflective (Gombert et al., 2004) or diffusing surfaces (Menez et al., 2008), and in the solar cell technology (light concentrators (Karp et al., 2010), and Sub-Wavelength Gratings SWG (Y. Kanamori et al., 2005)).

Beside optical applications, new applications have emerged from the spectacular properties of patterned surface when the size of patterns is reaching the nanometre scale. These properties can be superhydrophobicity, interaction with biofilms, nanotribology, etc... 
Finally, the development of photoresists for microelectronics applications has also accounted largely for the success of DUV interferometric lithography. This point will be developed below.

\subsection{D micro and nanostructures}

There are specific interests in developing 3D periodical structures. One of the most important applications is the fabrication of photonics crystals (PC). PCs are crystalline materials where the refractive index is periodically modulated on a length scale comparable to the light wavelength of interest. Interference of the light waves scattered from the dielectric lattice (i.e., Bragg scattering) leads to omnidirectional stop bands or photonic band gaps (PBGs), which are analogous to the electronic energy band gaps in a semiconductor. (Joannopoulos et al., 1995; Lin et al., 1998). PCs potentially offer revolutionary advances in the next-generation microphotonic devices and the integration of existing optoelectronic devices, including integrated optical circuits, lasers, sensing, spectroscopy, and pulse shaping.

In recent years there has been a considerable effort to develop novel methods for mass production of 3D PCs with controlled size, symmetry, and defect(s) on a large-scale basis (Moon \& Yang, 2009). Among others techniques, interferometric techniques appear very interesting since they are massively parallel techniques of microfabrication (unlike 2-photon fabrication), and they are potentially free of random defects (unlike self-assembly techniques). Several experimental configurations have been developed, including multibeam interference (Figure 2. Campbell et al., 2000; Yang et al., 2002) and mask interference lithography (Jeon et al., 2004).
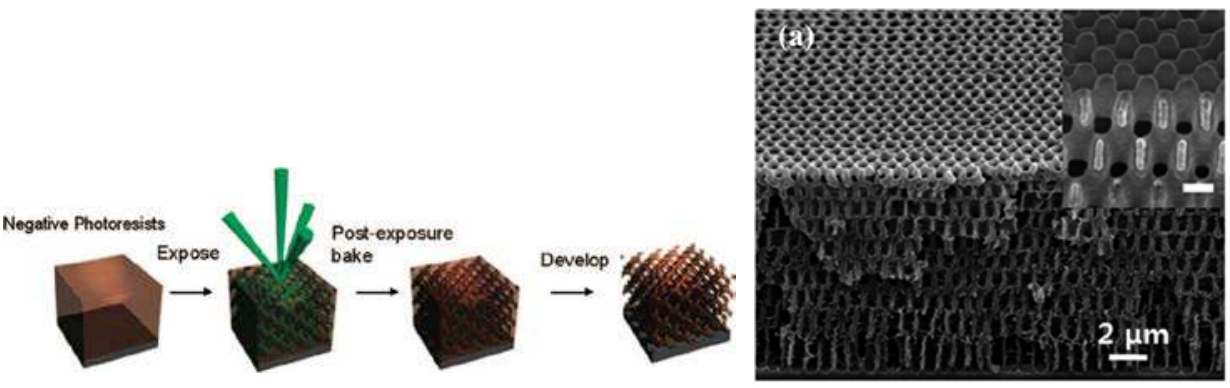

Fig. 2. Left) Holographic lithography process using an umbrella-like four beam setup, forming diamond- like interference patterns (Moon \& Yang, 2009); Right) Structure and optical reflectance of 3D hydrogel PCs via holographic lithography (Kang et al., 2008).

Many different materials have been proposed for the fabrication of 3D structures. Most of these materials are sensitive in the UV or visible range of wavelengths (Moon \& Yang, 2009) since the requirements in terms of period are not targeting the highest resolutions. Recently, a 3D "woodpile" structure with $1.55 \mu \mathrm{m}$ lattice constant and a $2 \mathrm{~mm}-$ by- $2 \mathrm{~mm}$ pattern area was demonstrated using DUV wavelengths (Yao et al., 2008).

\subsection{Wide surface micro and nanopatterning}

Applications of nanopatterned substrates in practical application in optics or biology require the generation of nanopatterns over wide surfaces. Such requirements are specially needed 
for applications in displays, light concentrators for solar cells, displacement sensors or compression of high power laser pulses (Figure 3). The extension of nanostructures over meter square area has generated many efforts. The Fraunhofer Institute fur Solare Energiesysteme (ISE, Freiburg en Brisgau) developed a holographic tool (Holotool) based on a Mach-Zender configuration with an irradiation surface greater than $1 \mathrm{~m}^{2}$. The Lawrence Livermore National Laboratory, in Livermore (Califormia, USA), has developed also an interference lithographic tool compatible with substrates as wide as $80 \mathrm{~cm}$. In both case, the requirements of environmental conditions stability (temperature, mechanical vibrations, etc...) are extremely severe and despite sophisticated monitoring and correctives devices, the resolutions are limited to periods greater than $200 \mathrm{~nm}$.

A very interesting alternative has been proposed at Massachusetts Institute of Technology, named Scanning Beam Interference Lithography (SBIL). The principle consists in generating a small area interferometric pattern and then, scans the surface to cover a wide substrate. The main difficulty relies on insuring a controlled displacement at the nanoscale of the writing interferometric head over $1 \mathrm{~m}^{2}$. This is achieved thanks to the development of a sophisticated interferometric displacement sensor. This technique allowed producing 900 $\mathrm{mm} \times 500 \mathrm{~mm}$ gratings.
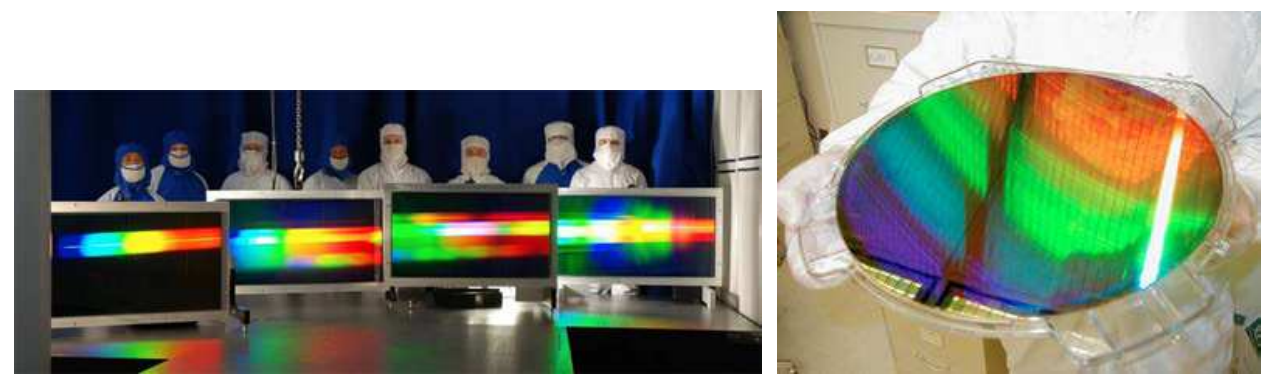

Fig. 3. Left) Multilayer dielectric diffraction gratings produced for NIF's Advanced Radiographic Capability petawatt laser have record size, damage resistance and efficieny (www.lasers.llnl.gov) and right) a $300 \mathrm{~mm}$-diameter silicon wafer patterned with a $400 \mathrm{~nm}$ period grating by the Nanoruler (http://snl.mit.edu/).

\section{Polymer-based materials for DUV interferometry lithography}

\subsection{Chemically amplified photoresists for applications in microelectronics}

Polymers are probably the most widely used materials for nanopatterning and many different strategies have been developed to achieve a spatial control of the material deposition down to the nanoscale.

As already mentioned previously, Deep-UV (DUV) photolithography has become the current technique used in the industry of microelectronics for production of sub-micron structures. In this field, Chemically Amplified Photoresists (CAR) are the predominant materials used in the fabrication of nanoscale structures with $193 \mathrm{~nm}$ photolithography (Bowden \& Turner, 1988; Macdonald et al., 1994). Patterns are defined chemically through the production of acid in areas exposed to DUV light (Figure 4) and an acid-catalyzed deprotection reaction that changes the solubility of the reacted material in an aqueous base solution (Ito, 2005). The patterning process is complex since many composition and 
process parameters have an impact on the photolithographic performances of the photoresist. Among those parameters, those linked to the resist materials are considered as the most critical. Three factors are essential to consider: resolution limit, sensitivity and line-width roughness (LWR). Resolution limit is the most important criterion since the new platforms of resists should be able to address the challenging next lithographic nodes under $45 \mathrm{~nm}$. However, sensitivity is a parameter of importance for practical applications due to the necessity to achieve short exposure times. Line width roughness (LWR) and line edge roughness (LER), measuring the deviation from an atomically smooth surface have also become new parameters preventing the feasibility of smaller feature sizes (Yoshimura et al., 1993).

a)

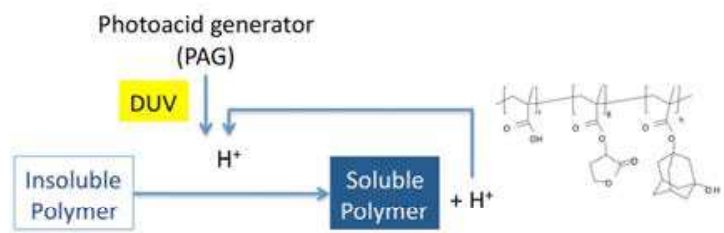

b)
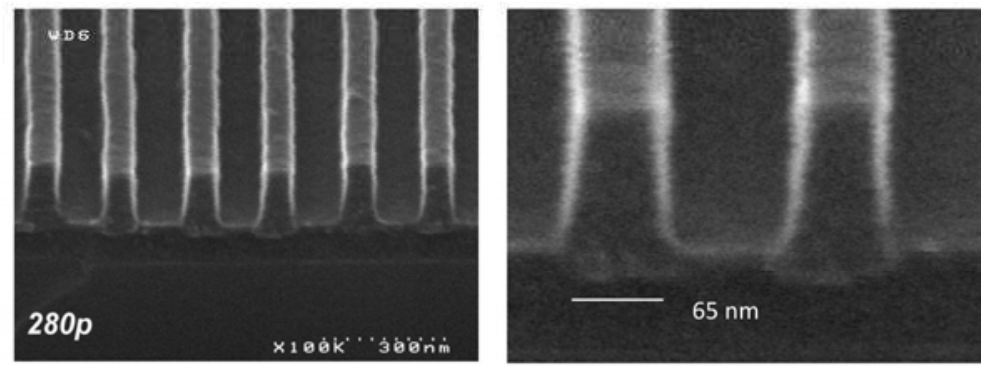

Fig. 4. a) Molecular mechanism of photoinduced modification of CAR photoresists (positive tone resist). b) SEM images of typical samples prepared by DUV interferometric lithography.

These material requirements for the next generations of DUV lithography have justified the recent efforts to develop innovative photoresists. The cost of industrial lithography tools destined at microelectronics applications (few tens of $\mathrm{M} \$$ ) is hardly compatible with timeconsuming and potentially contaminant resist development experiments. This is one of the reasons explaining the success of DUV interferometric lithography for developing new photoresists since this tool is relatively easy to install with a reasonable cost, and however, it provides resolutions in the range of the most advanced DUV industrial lithographic tools (few tens of $\mathrm{nm}$ ). Moreover, immersion lithography or double patterning can be proceeded. The nature of the polymer significantly contributes to all aspects of resist characteristics and performance. Most of the polymers used as resists are linear copolymers or terpolymers synthesized by the free radical polymerization technique (Ito, 2005; Kang et al., 2006). Such technique has the advantage to be relatively simple but the main drawback is a limited control of the polymer chain structure.

Advanced polymer synthesis strategies like Atom Transfer Radical Polymerization (ATRP) were recently proposed to achieve a better control of the polymer structure, with both linear and hyperbranched structure and for a large variety of monomers (Xia \& Matyjaszewski, 2001; 
Chochos et al., 2009). Interestingly, a correlation can be obtained between the polymer molecular weight, the chemical composition of the polymer and its polydispersity and its performance in photolithography, for linear and branched polymers, demonstrating the interest of a precise of the polymer molecular structure for nanolithography. (Ridaoui et al., 2010).

\subsection{Molecular glass photoresists}

Amorphous molecular glasses were recently proposed as a promising class of photoresists matrixes in addition to the traditional polymeric materials. They are amorphous materials with low molecular weight and designed for DUV, Extreme-UV (EUV) or e-beam lithography (Tsuchiya et al., 2005). Low molecular weight materials can form a stable glass above room temperature and they offer several advantages over traditional linear polymers as patterning feature size decreases. Compared to polymeric resists, molecular glasses provide better control of molecular structure and a broader range of building blocks. The recourse to molecular elementary building blocks allows reducing the variations in line width roughness (LWR) and line edge roughness (LER). In addition, the small uniform molecular size offers excellent processability, flexibility, transparency and uniform dissolution properties based on elemental composition.

Many different molecular structures have been proposed recently. Among other works, Figure 5 illustrates 2 examples. First example is based on an Adamantane architecture (Tanaka \& Ober, 2006). Adamantane structure brings both high transparency at $193 \mathrm{~nm}$ wavelength and high etch resistance by the cage structure. The second example is a 3component system composed of a monomer, a crosslinker and a photoacid generator.

Upon irradiation, photoacid is generated in the exposed region. Cross-linking reactions between the TMMGU cross-linker and the hydroxy groups on the monomer are catalyzed by the acid generated during the post-exposure baking period. The resulting cross-linked oligomers are insoluble in aqueous base, thus providing the solubility switch required for development. This system is capable of producing $60 \mathrm{~nm}$ line/space patterns (Yang et al., 2006).

a)

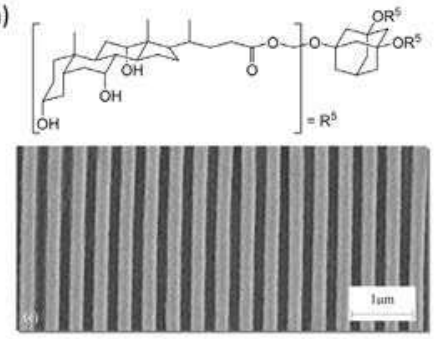

b)

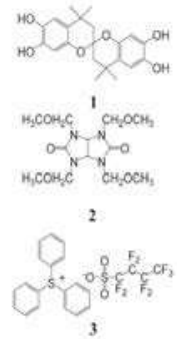

Fig. 5. a) Adamantane based molecular glass photoresist (from Tanaka \& Ober, 2006) and b) Components of negative-tone molecular glass resist: monomer (1), TMMGU cross-linker (2), and photoacid generator (3) (Yang et al., 2006).

\subsection{Plasma polymer for micro and nanopatterned surfaces}

The examples given in the previous parts are in relation with applications in microelectronics that are obviously the most important applications. Besides the fabrication of nanostructures by lithography, the generation of functional materials with chemical control at the nanoscale has drawn considerable interest during the last years. 
One of the most important objectives is to propose fast and easy processes to generate hydrophilic/hydrophobic surfaces with nanoscale lateral resolution possibly coupled with topography generation. Such surfaces are of importance for controlled deposition of nanoobjects, for applications in biology, or sensors.

In this context, polymers deposited by plasma polymerization have proved to be relevant since they present the following inherent advantages: i) the plasmachemical surface functionalization step is substrate-independent (Boening, 1988), ii) the plasma polymer thin film provides a good adhesion with most of the substrates (Roucoules et al., 2007), iii) the surface density of immobilized molecular species can be finely tuned by varying the pulsed plasma duty cycle (Teare et al., 2002; Oye et al., 2003) and iv) the plasma polymerization step is easily scaled up to industrial dimension (Yasuda \& Matsuzawa, 2005).

It was recently demonstrated that Deep-UV lithography could be used to generate topography patterns at the surface of maleic anhydride-based plasma polymers with typical dimension down to $75 \mathrm{~nm}$ (Soppera et al., 2008). Macroscopic spectroscopic characterization demonstrated that the surface chemistry was affected by DUV-irradiation (Figure 6). The choice of maleic anhydride-based polymer was guided by the reactivity of anhydride moieties that allows the introduction of further functionalities and/or immobilization of bioactive molecules using different binding strategies. These options are very valuable for the preparation of model substrates for fundamental studies on biointerfacial phenomena as well as for the controlled surface modification of a great variety of bulk substrates.
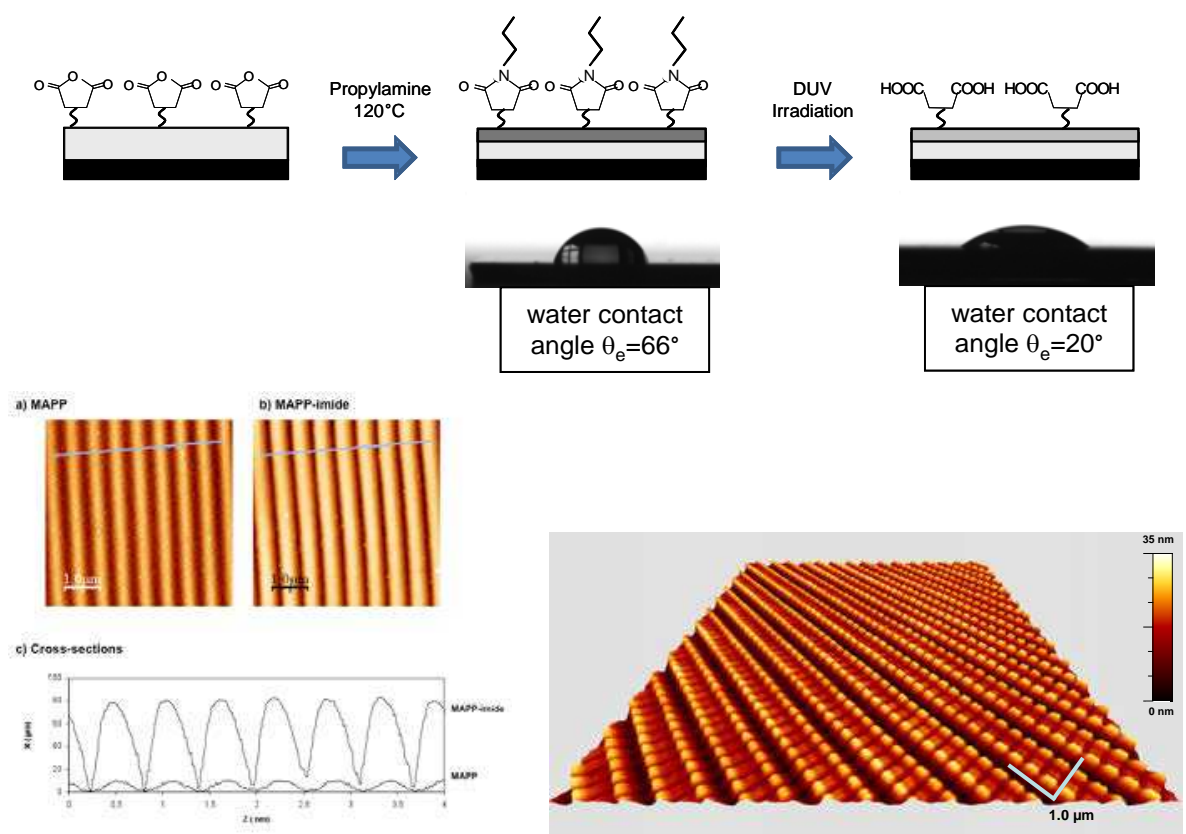

Fig. 6. Plasma polymer thin film preparation and surface chemistry characterization (Soppera et al., 2008; Dirani et al., 2010) 
It was also demonstrated that the DUV patterning allows creating topographic nanopatterns associated to a precise tuning of the local surface chemistry (Dirani et al, 2010a; Dirani et al., 2010b; Soppera et al., 2008). The control of the surface chemistry contrast was achieved by a new method using Atomic Force Microscopy in Pulsed Force Mode with plasma polymer functionalized tips (Figure 7).

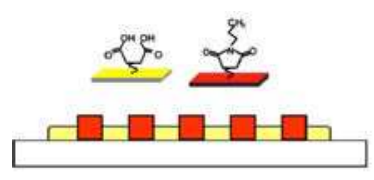

Acid functionalized tip

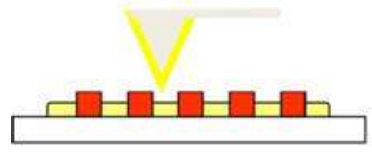

Imide functionalized tip

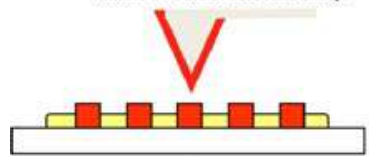

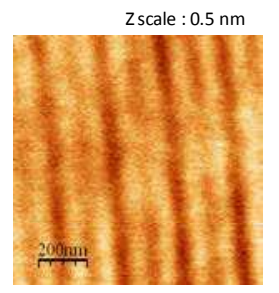

$\Delta$ pull-off $=8 \mathrm{nN}$

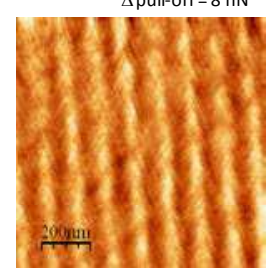

a) $0.75 \mathrm{~mJ} / \mathrm{cm}^{2}$

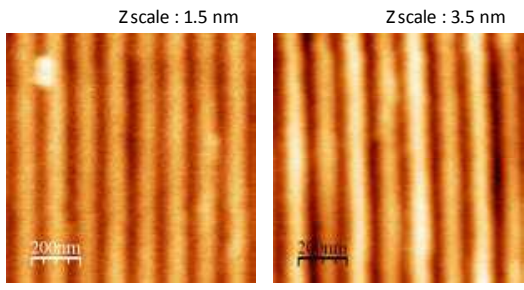

$\Delta$ pull-off $=25 \mathrm{nN}$

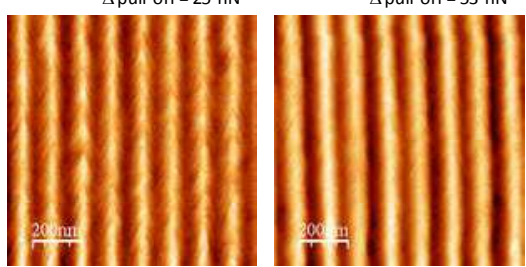

b) $1.50 \mathrm{~mJ} / \mathrm{cm}^{2}$

c) $3.75 \mathrm{~mJ} / \mathrm{cm}^{2}$

Fig. 7. PFM images of the imide plasma polymer surface for increasing DUV dose. The period of pattern was $150 \mathrm{~nm}$. An imide terminated tip was used for surface probing in air. First raw is the topography image. Last raw shows the local pull-off force. Doses of a) 0.75 $\mathrm{mJ} / \mathrm{cm}^{2}$, b) $1.50 \mathrm{~mJ} / \mathrm{cm}^{2}$ and c) $3.75 \mathrm{~mJ} / \mathrm{cm}^{2}$ were used (Dirani et al., 2010)

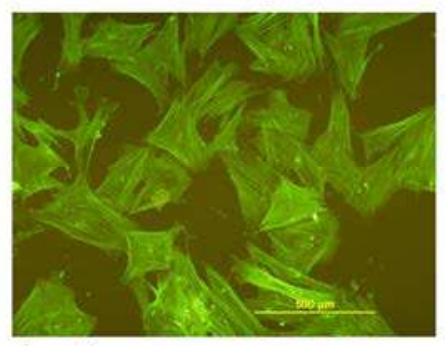

No pattern

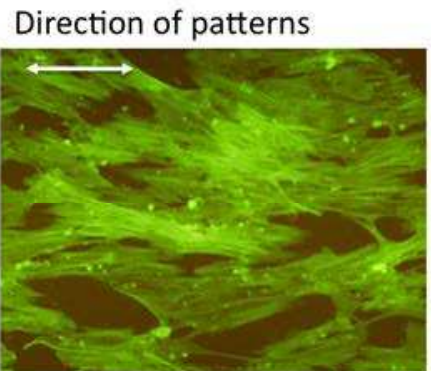

Patterns (Width: $1.5 \mu \mathrm{m}$ - Height: $40 \mathrm{~nm}$ )

Fig. 8. Comparison of human osteoprogenitor cells development on non-patterned (left) and patterned (right) plasma polymer surface (Ploux et al., 2009).

These chemically and topographically patterned surfaces have high potential as model surfaces for studying cell and bacteria responses to surface chemistry and surface topography. Biological experiments were conducted on patterned maleic anhydride plasma polymer thin films using human osteoprogenitor cells and Escherichia coli K12 (Ploux et al., 2009). Proliferation and orientation of cells and bacteria were analyzed and discussed according to the size and the chemistry of the features. This work showed interesting 
opposite behavior of bacteria compared to eukaryotic cells, in response to the surface chemistry and to the surface topography. This result may be particularly useful on medical implants design.

\section{Inorganic materials for DUV interferometry lithography}

\subsection{Introduction}

Despite many advantages listed below, organic-based polymers have specific limitations like poor mechanical properties, low refractive index and thus, there is a major interest to develop non-organic materials suitable for nanofabrication. In this context, metal oxides present many advantages. As an example, Zirconium dioxide $\left(\mathrm{ZrO}_{2}\right)$ has unique properties such as high refractive index, wide optical band gap, low absorption and dispersion in the visible and near-infrared spectral regions, as well as high chemical and thermal stabilities. Other metal oxides like $\mathrm{TiO}_{2}, \mathrm{HfO}_{2}, \mathrm{ZnO}$ have many applications in fields like photocatalysis, photovoltaic, displays, biology, optics, and photonics... (Lebeau \& Innocenzi, 2010) and require convenient techniques for nanopatterning.

The chemical sol-gel process is probably the most attractive route to elaborate inorganic thin films due to its powerful control on the structural and properties of films, low-cost, and abilities to deal with substrates of large area and/or complex shape (Judenstein \& Sanchez, 1996). It is a versatile process that can be adapted for a wide range of oxides ( $\mathrm{Si}, \mathrm{Zr}, \mathrm{Ti}, \mathrm{Hf}$, $\mathrm{Zn}$ ) using simple deposition techniques (dip-coating, spin-coating) and relatively low curing temperatures (few hundreds of ${ }^{\circ} \mathrm{C}$ ). Basically, sol-gel chemistry is based on the succession of hydrolysis and condensation reactions as follow:

Hydrolysis

$$
\begin{aligned}
& \mathrm{M}(\mathrm{OR})_{4}+\mathrm{H}_{2} \mathrm{O} \rightarrow \mathrm{HO}-\mathrm{M}(\mathrm{OR})_{3}+\mathrm{R}-\mathrm{OH} \\
& \mathrm{M}(\mathrm{OR})_{4}+4 \mathrm{H}_{2} \mathrm{O} \rightarrow \mathrm{M}(\mathrm{OH})_{4}+4 \mathrm{R}-\mathrm{OH}
\end{aligned}
$$

Condensation

$$
\begin{aligned}
& (\mathrm{OR})_{3}-\mathrm{M}-\mathrm{OH}+\mathrm{HO}-\mathrm{M}-(\mathrm{OR})_{3}->\quad\left[(\mathrm{OR})_{3} \mathrm{M}-\mathrm{O}-\mathrm{M}(\mathrm{OR})_{3}\right]+\mathrm{H}-\mathrm{O}-\mathrm{H} \\
& (\mathrm{OR})_{3}-\mathrm{M}-\mathrm{OR}+\mathrm{HO}-\mathrm{M}-(\mathrm{OR})_{3}->\quad\left[(\mathrm{OR})_{3} \mathrm{M}-\mathrm{O}-\mathrm{M}(\mathrm{OR})_{3}\right]+\mathrm{R}-\mathrm{OH}
\end{aligned}
$$

Where $\mathrm{M}$ stands for different elements ( $\mathrm{Si}, \mathrm{Zr}, \mathrm{Ti}$...)

Usually the crosslinking of the layer is achieved by thermal process. In this case, the process is not compatible with photopatterning at the micro or the nanoscale. Several strategies have been developed to achieve patterning on sol-gel deposited thin metal oxide layers. Some examples for $\mathrm{ZrO}_{2}$ are given in (Thomas, 1994; Belleville et al., 2000; Belleville et al., 2003; Zhang et al., 2000; Tian et al. 2005). Usually they rely on complex multistep processes, such as photolithographic patterning and chemical etching or lift-off. These methods often use sacrificial masking materials and the transfer step induces a loss of resolution.

There is thus a major challenge to develop direct means for nanopatterning. One way consists in proposing hybrid materials based on precursors combining an inorganic function and a photopolymerizable one (Soppera et al., 2003; Matejka et al., 2004). The main limitation of this route is to finally provide a hybrid material with a relatively high proportion of organic part. 


\subsection{Nanopatterning of hybrid precursors by DUV interferometry}

In order to obtain inorganic nanostructures, sol-gel-based spin-coatable precursor of $\mathrm{ZrO} 2$ that is not only amenable to direct-write using DUV lithography but is also capable of providing nanoscale resolution was proposed. (Ridaoui et al., 2010)

The crosslinking photoreaction relies on a direct photolysis of the complexed $\mathrm{Zr}$ atom. The interaction between UV light and metal alkoxide complex has been already described : after light absorption, charge transfer complexes can be created and they can induce a photolysis of the ligand (Versace et al., 2008). For Titanium alkoxides, it has been proved that Ti-oxo complex gave rise to a decarboxylation reaction (Hundiecker reaction (Soppera et al., 2001)). In the present case, we can assume that the same kind of mechanism occurs, leading to the production of reactive $\mathrm{Zr}$ species that can react on free alkoxides functions to create a tridimensional $\mathrm{ZrO}_{2}$ network (Figure 9).

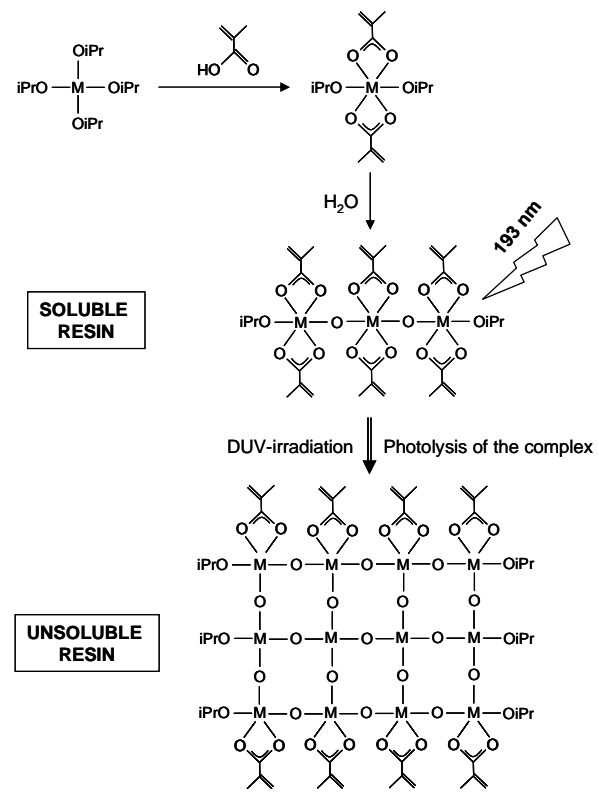

Fig. 9. Schematic representation of the material preparation and modification under DUV irradiation of the negative tone inorganic resist. $\mathrm{M}$ is a transition metal $(\mathrm{Zr}, \mathrm{Ti}$...). As shown in this scheme, the DUV irradiation results in condensation of the partially condensed metal alkoxide precursors resulting in a modification of solubility of the thin film (Ridaoui et al., 2010)

The main interest of this negative tone resist relies on the possibility to remove the organic part and obtain $\mathrm{ZrO}_{2}$ after thermal treatment. The AFM scan of the sample is plotted in Figure 10. It can be observed that the patterns remained perfectly defined after the thermal treatment, opening a very convenient way to produce micro or nanostructures. Applications of such nanostructures with high refractive index are expected in the field of optics and photonics. Many applications of such technology are also expected in all applications fields in which robust nanostructures with inertness towards chemical, temperature, and pressure are needed such as photovoltaic, photocatalysis or biology. 

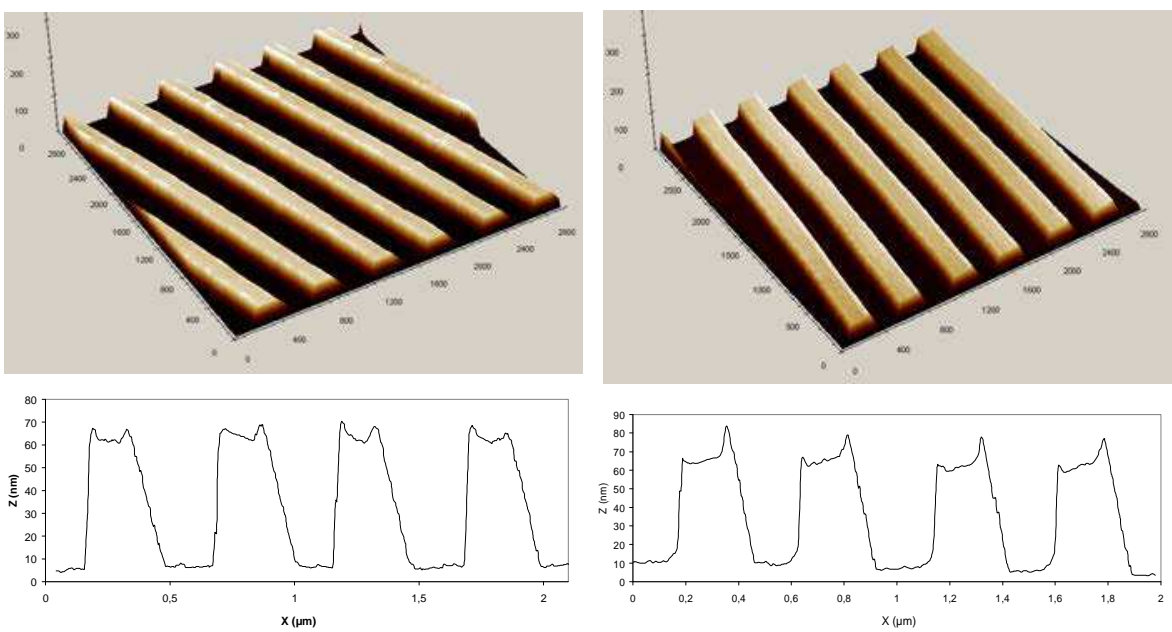

Fig. 10. AFM image of a periodic patterns written on the Zr sol-gel film. Period was $500 \mathrm{~nm}$. Left) represent the grating before thermal heating, and Right) is a grating after thermal heating $\left(600^{\circ} \mathrm{C}, 2\right.$ hours).

\section{Conclusion}

The development of large-area, high-resolution nanostructures is a challenging problem that must be addressed for applications in high performance nanoscale devices, such as nanoelectronics, optics, microfluidics, organic solar cell, display devices and biosensing devices. Today's challenges are not limited to the resolution issue but many others aspects are to be considered. In particular, there is a growing need for simple processes enabling integration of functional materials.

With this regards, DUV interferometric lithography techniques are still of high interest, as illustrated in this chapter. The recourse to advanced optical setup and immersion allow creating patterns with typical dimensions much smaller than $100 \mathrm{~nm}$ on the basis of many different materials. This photon-based technique is thus competitive in terms of resolution with other advanced nanofabrication techniques and because it is a massively parallel technology to produce nanoparts on a large substrate, it is well-complementary to e-beam, ion-beam or nanoimprint.

\section{Acknowledgment}

Agence Nationale pour la Recherche (ANR - Projects NANORUGO, HOLOSENSE and NIROPTICS), CNRS and Région Alsace are gratefully acknowledged for financial supports

\section{References}

Archambault, J.-L.; Reekie L. \& Russell, P.St.J. (1993). 100\% reflectivity Bragg reflectors produced in optical fibres by single excimer laser pulses. Electron. Lett., Vol.29, No.5, (March 1993), pp. 453-455 
Askins, G.; Tsai, T.-E.; Williams, G.M.; Putnam, M.A.; Bashkansky M. \& Friebele E.J. (1992). Fiber Bragg reflectors prepared by a single excimer pulse. Optics Lett., Vol.17, No.11, (1992), pp. 833-835

Belleville, P.; Bonnin, C. \& Priotton, J.J. (2000). Room-Temperature Mirror Preparation Using Sol-Gel Chemistry and Laminar-Flow Coating Technique. J. Sol-gel Sci. Technol, Vol.19, No.1-3, (2000), pp. 223-226

Belleville, P.; Prené, P. ; Bonnin, C. ; Beaurain, L. ; Montouillout, Y. \& Lavastre, E. (2003). Proc. SPIE, 5250, 196

Boening, H.V. (1988). Fundamental of plasma chemistry and technology, Technomic Publishing Company, Inc., 1988, p. 75.

Bourgin, Y.; Bakkali, S.; Jourlin, Y.; Tonchev, S. \& Parriaux, O. (2009). Monolithic doublegrating phase mask for large-period highly coherent grating printing. Optics Letters, Vol.34, No.24, (2009), pp. 3800-3802

Bourov, A.; Fan, Y.; Cropanese, F.C.; Lafferty, N.V.; Zavyalova, L.V.; Kang., H.; Smith, B.W. (2004). Immersion microlithography at $193 \mathrm{~nm}$ with a Talbot prism interferometer. Proc. SPIE, vol. 5377, (2004), p. 1573.

Bowden, M. J. \& Turner, S. R. (1988) Electronic and photonic applications of polymers. ACS Adv. Chem. Ser., Washington (1988) 218, 109.

Braun D., (2002). Semiconducting polymer LEDs. Materials Today, Vol.5, No.6, (June 2002), pp. 32-39

Cai Y. \& Ocko B. (2005). Electro Pen Nanolithography. J. Am. Chem. Soc., Vol.127, No.46, (October 2009), pp. 16287-16291

Campbell, M.; Sharp, D. N.; Harrison, M. T.; Denning, R. G. \& Turberfield, A. J. (2000). Fabrication of photonic crystals for the visible spectrum by holographic lithography. Nature, Vol.404, (March 2000), pp. 53-56

Charley, A.L.; Lagrange, A.; Lartigue, O.; Bandelier, P.; Derouard, M \& Schiavone, P. (2006). Liquid Immersion Lithography at $193 \mathrm{~nm}$ Using a High-NA Achromatic Interferometer, Proc. of SPIE Vol. $615461541 \mathrm{Z}$

Chochos, C. L.; Ismailova, E.; Brochon, C.; Leclerc, N.; Tiron, R.; Sourd, C.; Bandelier, P.; Foucher, J.; Ridaoui, H.; Dirani, A.; Soppera, O.; Perret, D.; Brault, C.; Serra, C. A. \& Hadziioannou, G. (2009). Hyperbranched Polymers for Photolithographic Applications : Towards Understanding the Relationship between Chemical Structure of Polymer Resin and Lithographic Performances. Advanced Materials, Vol.21, No.10-11, (2009), pp. 1121-1125

Christman K.L., Schopf E., Broyer R.M., Li R.C., Chen Y. \& Maynard H.D. (2009). Positioning Multiple Proteins at the Nanoscale with Electron Beam Cross-Linked Functional Polymers. J. Am. Chem. Soc. Vol.131, No.2, (December 2008), pp. 521-527

Cotton D. V., Fell C.J. \& Dastoor P.C. (2009). Fabricating semi-conducting polymer photonic structures via near-field scanning optical lithography. Synthetic Metals. Vol.159, No.5-6, (March 2009), pp. 456-461

Dirani, A.; Roucoules, V.; Haidara, H. \& Soppera, O. (2010). Plasma polymer tailoring of the topography and chemistry of surfaces at the nanoscale. Langmuir, Vol.26, No.22, (October 2010), pp. 17532-17539

Dirani, A.; Wieder, F.; Roucoules, V.; Airoudj, A. \& Soppera, O. (2010). Nanopatterning of Plasma Polymer Thin Films by ArF Photolithography: Impact of Polymer Structure 
on Patterning Properties. Plasma Processes and Polymers, Vol. 7, No.7, (February 2010), pp.571-581

Dyer, P.E.; Farley, R.J. \& Giedl, R. (1995). Analysis of grating formation with excimer laser irradiated phase masks. Opt. Comm. Vol.115, No.3-4, (August 2005), pp 327-334

El Ahrach H., Bachelot R., Vial A., Lerondel G., Plain J., Royer P. \& Soppera O. (2007). Spectral Degeneracy Breaking of the Plasmon Resonance of Single Metal Nanoparticles by Nanoscale Near-Field Photopolymerization. Phys. Rev. Lett., Vol.98, No.10, (March 2007), pp. 107402-1-107402-2

Fan H. J., Werner P. \& Zacharias M. (2006). Semiconductor Nanowires: From SelfOrganization to Patterned Growth. Small. Vol.2, No.700, (March 2006), pp. 700-717

Gombert A., Benedikt B., Christopher B., Peter N., Jörg M., Wolfgang H. \& Michael N., (2004), Replicated microstructures with optical functions in solar and display applications (Proceedings Paper). Optical Engineering, Vol.43, No.22, (December 2003), pp. 2525-2533

Gonsalves K.E., Wang M., Lee C.T., Yueh W., Tapia-Tapia M., Batina N. \& Henderson C.L. (2009). Novel chemically amplified resists incorporating anionic photoacid generator functional groups for sub-50-nm half-pitch lithography. J. Mater. Chem. Vol.19, (March 2009), pp. 2797-2802

Graeter S.V., Huang J., Perschmann N., Lopez-Garcia M., Kessler H., Ding J. \& Spatz J.P. (2007). Mimicking Cellular Environments by Nanostructured Soft Interfaces. Nano Letters, Vol.7, No.5, (March 2007), pp. 1413-1418

He X., Winkel J. \& Huck W.T. (2009). Nanopatterning via Pressure-Induced Instabilities in Heilmann, R.K.; Akilian, M.; Chang, C.H.; Fleming, R.; JOO, C.; Montoya, J.C.; Torkmann, A. \& Schattenburg, M.L. (2004). MIT CSR IAP 1-Lectures series Frontiers of Astronomy, Astrophysics and Space Sciences.

Henzie J., Barton J. E., Stender C. L. \& Odom T. W. (2006). Large-area nanoscale patterning: chemistry meets fabrication. Accounts of Chemical Research. Vol.39, No.4, (January 2006), pp. 249-257

Huh J.W., Jeong J. W., Lee J.W., Shin S.I., Kwon J.H., Choi J., Yoon H.G., Cho G.I., You I.K., Kang S.Y. \& Ju B.K. (2009). Carbon nanotube and conducting polymer dual-layered films fabricated by microcontact printing. Appl. Phys. Lett. Vol.94, (June 2009), pp. 223311-1-223311-2

Im S.G., Kim B.S., Tenhaeff W.E., Hammond P.T. \& Gleason K.K. (2009). A directly patternable click-active polymer film via initiated chemical vapor deposition (iCVD). Thin Solid Films. Vol.517, No12, (January 2009), pp. 3606-3611

Ito H., (2005). Chemical amplification resists for microlithography. Advances in Polymer Science, Vol.172, No.276, (2005), pp. 37-245.

Jegadesan S., Sindhu S., Advincula R.C. \& Valiyaveettil S. (2006). Direct Electrochemical Nanopatterning of Polycarbazole Monomer and Precursor Polymer Films: Ambient Formation of Thermally Stable Conducting Nanopatterns. Langmuir, Vol.22, (November 2005), pp. 780-786

Jeon, S.; Menard, E.; Park, J. U.; Maria, J.; Meitl, M.; Zaumseil, J. \& Rogers, J. A. (2004). Three-Dimensional Nanofabrication with Rubber Stamps and Conformable Photomasks. Adv. Mater., Vol.16, No.15, (August 2004), pp. 1369-1373

Joannopoulos, J. D.; Meade, R. D. \& Winn, J. N. (1995). Photonic Crystals; Princeton University Press: Princeton, NJ, 1995. 
Judeinstein, P. \& Sanchez, C. (1996). Hybrid Organic-Inorganic Materials : A Land of Multidisciplinarity. J. Mater. Chem., Vol.6, No.4, (1996), pp. 511-525

Kamigaito M., Ando T. \& Sawamoto M., (2001). Metal-Catalyzed Living Radical Polymerization. Chem. Rev., Vol.101, No.12, (December 2001), pp. 3689-3746

Kanamori Y., Roy E., Chen Y., (2005). Antireflection sub-wavelength gratings fabricated by spin-coating replication. Microelectronic Engineering, Vol.78-79, (March 2005), pp. 287-293

Kang S. H., Prabhu V. M., Vogt B. D., Lin E. K., Wu W.-L. \& Turnquest K., (2006). Effect of copolymer composition on acid-catalyzed deprotection reaction kinetics in model photoresists. Polymer, Vol.47, No.18, (August 2006), pp. 6293-6302

Kang, J. H.; Moon, J. H.; Lee, S. K.; Park, S. G.; Jang, S. G.; Yang, S. \& Yang, S. M. (2008). Thermoresponsive Hydrogel Photonic Crystals by Three-Dimensional Holographic Lithograph. Adv. Mater., Vol.20, No.16, (August 2008), pp. 3061-3065

Karp, Jason H., Tremblay, Eric J., Ford \& Joseph E., (2010). Planar micro-optic solar concentrator. Optics Express, Vol.18, No.2, (January 2010), pp. 1122-1133

Lebeau, B \& Innocenzi, P. (2011). Hybrid materials for optics and photonic. Chemical Society Review, Vol.40, No.2, (2011), pp. 886-906

Lee W.K., Whitman L.J., Lee J., King W.P. \& Sheehan P.E. (2008). The nanopatterning of a stimulus-responsive polymer by thermal dip-pen nanolithography. Soft Matter, Vol.4, No.9, (2008), pp. 1844-1847

Lin, S. Y.; Fleming, J. G.; Hetherington, D. L.; Smith, B. K.; Biswas, R.; Ho, K. M.; Sigalas, M. M.; Zubrzycki, W.; Kurtz, S. R. \& Bur, J (1998). A three-dimensional photonic crystal operating at infrared wavelengths. Nature, Vol.394, (July 1998), pp. 251-253

Macdonald S. A., Wilson C. G. \& Fréchet J. M. J., (1994). Chemical Amplification in HighResolution Imaging Systems. Acc. Chem. Res. Vol. 27, No.6, (June 1994), pp. 151-158

Matejka, L.; Strachota, A.; Plestil, J.; Whelan, P.; Steinhart, M. \& Slouf, M. (2004). Epoxy Networks Reinforced with Polyhedral Oligomeric Silsesquioxanes (POSS). Structure and Morphology. Macromolecules, Vol.37, No.25, (November 2004), pp. 9449-9456

Menez, L.; Mulet, J.P.; Lalanne, P. (2008). Patent WO/2008/145895 Light Scattering Network

Mihailov, S.J.; \& Gower, M.C. (1994). Recording of efficient high-order Bragg reflectors in optical fibres by mask image projection and single pulse exposure with an excimer laser. Electron. Lett., Vol.30, No.9, (April 1994), pp. 707-709

Moon, J.H. \& Yang, S. (2009). Chemical Aspects of Three-Dimensional Photonic Crystals. Chem. Rev., Vol.110, No.1, (August 2009), pp. 547-574

Moore G. E. (1965). Cramming More Components Onto Integrated Circuits. Electronics, Vol.38, No.8, (April 1965, pp. 114-117

Nie Z. \& Kumacheva E. (2008). Patterning surfaces with functional polymers. Nature Mater.Vol.7, pp. 277-290

Oye, G. ; Roucoules, V. ; Oates, L.J.; Caameron, A.M.; Cameron, N.R.; Steel, P.G.; Badyal, J.P.S.; Davis, B.G.; Coe, D. M. \& Cox, R.A. (2003). Plasmachemical Amine Functionalization of Porous Polystyrene Spheres: The Importance of Particle Size. J. Phys. Chem. B., Vol.107, No.15, (2003), pp. 3496-3499

Ploux, L.; Anselme, K.; Dirani, A.; Ponche, A.; Soppera, O. \& Roucoules, V. (2009). Opposite Responses of Cells and Bacteria to Micro/Nanopatterned Surfaces Prepared by 
Pulsed Plasma Polymerization and UV-Irradiation. Langmuir, Vol. 25, No.14, (June 2009), pp. 8161-8169

Raub, A.K. \& Brueck, S.R.J. (2003). Deep UV immersion interferometric lithography. Proc of SPIE 2003, 5040, 667.

Ridaoui, H.; Dirani, A.; Soppera, O.; Ismailova, E.; Brochon, C.; Schlatter, G.; Hadziioannou, G.; Tiron, R.; Bandelier, P. \& Sourd, C. (2010). Chemically amplified photoresists for 193-nm photolithography: Effect of molecular structure and photonic parameters on photopatterning. J. Polym. Sci. Part A: Polym. Chem.", Vol.48, No.6, (February 2010), pp. 1271-1277

Ridaoui, H.; Wieder, F.; Ponche, A. \& Soppera, O. (2010). Direct ArF laser photopatterning of metal oxide nanostructures prepared by the sol-gel route. Nanotechnology, Vol.21, No.6, (January 2010), pp. 065303

Roucoules, V.; Ponche, A.; Siffer, F.; Ergurrolla, U. \& Vallat, M. F. (2007). Strengthening the Junction Between EPDM and Aluminium Substrate via Plasma Polymerisation. J. Adhes. Vol. 83, No.10, (2007), pp. 875-895

Santillan, J.; Otoguro, A.; Itani, T.; Fujii, K.; Kagayama, A.; Nakano, T.; Nakayama, N.; Tamatani, H. \& Fukuda, S. (2006). A study of 193-nm immersion lithography using novel high refractive index fluids. Microelectronics Engineering, Vol.83, No.4-9, (September 2006), pp. 651-654

Schon J.H., Kloc C., Dodabalapur A. \& Batlogg B., (2000). An Organic Solid State Injection Laser. Science, Vol.289, No.5479, (July 2000), pp. 599-601

Seo K. \& Borguet E. (2006). Nanolithographic Write, Read, and Erase via Reversible Nanotemplated Nanostructure Electrodeposition on Alkanethiol-Modified Au(111) in an Aqueous Solution. Langmuir, Vol.22, No.4, January 2006), pp 1388-1391

Soppera O., Jradi S. \& Lougnot D.J. (2008). Photopolymerization with microscale resolution: Influence of the physico-chemical and photonic parameters. J. Polym. Sci. Part A: Polym. Chem., Vol.46, No.11, (April 2008), pp. 3783-3794

Soppera, O. \& Croutxe-Barghorn C. (2003). Real-time Fourier transform infrared study of free-radical UV-induced polymerization of hybrid sol-gel. I. Effect of silicate backbone on photopolymerization kinetics. J. Polym. Sci., Part A : Polym. Chem., Vol.41, No.5, (January 2003), pp. 716-724

Soppera, O.; Croutxe-Barghorn \& C.; Lougnot, D.J. (2001). New insights into photoinduced processes in hybrid sol-gel glasses containing modified titanium alkoxides. New J. Chem., Vol.25, No.8, (2001), pp. 1006-1014

Soppera, O.; Dirani, A.; Ponche, A. \& Roucoules, V. (2008). Nanopatterning of plasma polymer reactive surfaces by DUV interferometry. Nanotechnology, Vol.19, No. 39, (August 2008), pp 395304-395312

Tanaka, S. \& Ober, C.K. (2003). Adamantane-based Molecular Glass Resist for 193nm Lithography Proc. of SPIE 2006, 6153.

Teare, D.O.H.; Spanos, C.; Ridley, P.; Kinmond, E.J.; Roucoules, V. \& Badyal, J.P.S. (2002). Pulsed plasma deposition of super-hydrophobic nanospheres. Chem. Mater. Vol. 14, No.11, (2002), pp. 4566-4571.

He, X.; Winkel, J.; Huck, W. Nanopatterning via Pressure-Induced Instabilities in Thin Polymer Films. Adv. Mater. Vol. 21, (March 2009), pp. 2083-2087

Thomas I.M. (1994). Preparation of dielectric highly reflective (HR) mirrors from colloidal oxide suspensions containing organic polymer binders. Proc. of SPIE 2288, 50 
Tian, G.L.; Huang, J.B.; Wang, T.; He, H.B. \& Shao, J.D. (2005). Microstructure and laserinduced damage threshold of $\mathrm{ZrO}_{2}$ coatings dependence on annealing temperature. Appl. Surf. Sci., Vol.239, No.2, (July 2004), pp. 201-208

Tsuchiya, K.; Chang, S. W.; Felix, N. M.; Ueda, M. \& Ober, C. K. (2005). Lithography Based on Molecular Glasses. Journal of Photopolymer Science and Technology, Vol.18, No.3, (May 2005), pp. 431-434

Versace, D.L.; Soppera, O.; Lalevée, J. \& Croutxe-Barghorn, C. (2008). Influence of zirconium propoxide on the radical induced photopolymerisation of hybrid sol-gel materials. New J. Chem, Vol.32, No.12, (2008), pp. 2270-2278

Wegmann G., Giessen H., Greiner A. \& Mahrt R.F., (1998). Laser emission from a solid conjugated polymer: Gain, tunability, and coherence. Phys. Rev. B, Vol.57, No.8, (February 1998), pp. R4218-R4221

Xia J. \& Matyjaszewski K., (2001). Atom Transfer Radical Polymerization. Chem. Rev., Vol.101, No.9, (February 2001), pp. 2921-2990

Xiong, Z.; Peng, G.D.; Wu, B. \& Chu, P.L. J. (1999). Effects of the zeroth-order diffraction of a phase mask on Bragg gratings. Lightwave Techn, Vol.17, No.11, (November 2002), pp. 2361-2365

Yang, D.; Chang, S.W. \& Ober, C.K (2006). Molecular glass photoresists for advanced lithography. J. Mater. Chem., Vol.16, No.18, (2006), pp. 1693-1696

Yang, S.; Megens, M.; Aizenberg, J.; Wiltzius, P.; Chaikin, P. M. \& Russel, W. B. (2002). Creating Periodic Three-Dimensional Structures by Multibeam Interference of Visible Laser. Chem. Mater. Vol.14, No.7, (June 2002), pp. 2831-2833

Yao, P.; Qiu, L.; Shi, S.; Schneider, G.J.; Prather, D.W.; Sharkawy, A. \& Kelmelis, E. (2008). Fabrication of 3D polymer photonic crystals for near-IR applications. Proc. SPIE, Vol.6883, (January 2008), pp. 688313-688319-9

Yasuda, H. \& Matsuzawa, Y. (2005). Economical Advantages of Low-Pressure Plasma Polymerization Coating. Plasma Process. Polym., Vol. 2, No.6, (July 2005), pp. 507-512

Yasuda, H. (1985). Plasma Polymerization; Academic Press: London, 1985.

Yen, A.; Anderson, E.H.; Ghanbari, R.A.; Schattenburg, M.L. \& Smith, H.I.; Achromatic holographic configuration for 100-nm-period lithography. Applied Optics Vol.31, No.22, (August 1992), pp. 4540-4545

Yoon B., Acharya H., Lee G., Kim H-C., Huh J. \& Park C. (2008). Nanopatterning of thin polymer films by controlled dewetting on a topographic pre-patter. Soft Matter, Vol.4, No.7, (2008), pp. 1467-1472

Yoshimura T., Shiraishi H., Yamamoto J. \& Okazaki S. (1993). Correlation of Nano Edge Roughness in Resist Patterns with Base Polymers. Jpn. J. Appl. Phys. Vol. 32,(August 2003), pp. 6065-6070

Zhang, Q.Y.; Shen, J.; Wang, J.; Wu, G.M. \& Chen, L.Y. (2000). Sol-gel derived $\mathrm{ZrO}_{2}-$ $\mathrm{SiO}_{2}$ highly reflective coatings. International Journal of Inorganic Materials, Vol.2, No.4, (April 2000), pp. 319-323 


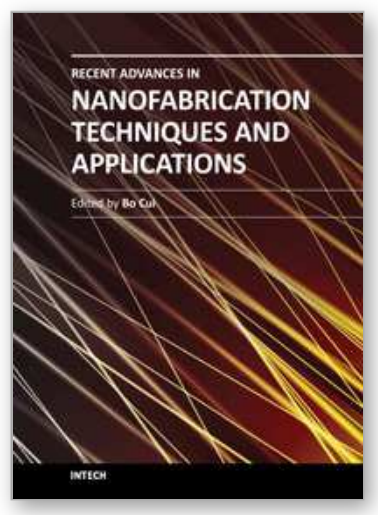

\author{
Recent Advances in Nanofabrication Techniques and Applications \\ Edited by Prof. Bo Cui
}

ISBN 978-953-307-602-7

Hard cover, 614 pages

Publisher InTech

Published online 02, December, 2011

Published in print edition December, 2011

Nanotechnology has experienced a rapid growth in the past decade, largely owing to the rapid advances in nanofabrication techniques employed to fabricate nano-devices. Nanofabrication can be divided into two categories: "bottom up" approach using chemical synthesis or self assembly, and "top down" approach using nanolithography, thin film deposition and etching techniques. Both topics are covered, though with a focus on the second category. This book contains twenty nine chapters and aims to provide the fundamentals and recent advances of nanofabrication techniques, as well as its device applications. Most chapters focus on indepth studies of a particular research field, and are thus targeted for researchers, though some chapters focus on the basics of lithographic techniques accessible for upper year undergraduate students. Divided into five parts, this book covers electron beam, focused ion beam, nanoimprint, deep and extreme UV, X-ray, scanning probe, interference, two-photon, and nanosphere lithography.

\title{
How to reference
}

In order to correctly reference this scholarly work, feel free to copy and paste the following:

Olivier Soppera, Ali Dirani, Fabrice Stehlin, Hassan Ridaoui, Arnaud Spangenberg, Fernand Wieder and Vincent Roucoules (2011). DUV Interferometry for Micro and Nanopatterned Surfaces, Recent Advances in Nanofabrication Techniques and Applications, Prof. Bo Cui (Ed.), ISBN: 978-953-307-602-7, InTech, Available from: http://www.intechopen.com/books/recent-advances-in-nanofabrication-techniques-and-applications/duvinterferometry-for-micro-and-nanopatterned-surfaces

\section{INTECH}

open science | open minds

\section{InTech Europe}

University Campus STeP Ri

Slavka Krautzeka 83/A

51000 Rijeka, Croatia

Phone: +385 (51) 770447

Fax: +385 (51) 686166

www.intechopen.com

\section{InTech China}

Unit 405, Office Block, Hotel Equatorial Shanghai

No.65, Yan An Road (West), Shanghai, 200040, China

中国上海市延安西路65号上海国际贵都大饭店办公楼405单元

Phone: +86-21-62489820

Fax: $+86-21-62489821$ 
(C) 2011 The Author(s). Licensee IntechOpen. This is an open access article distributed under the terms of the Creative Commons Attribution 3.0 License, which permits unrestricted use, distribution, and reproduction in any medium, provided the original work is properly cited. 